\title{
A Critical Role for Dorsal Progenitors in Cortical Myelination
}

\author{
Tao Yue, ${ }^{1}$ Kendy Xian, ${ }^{1}$ Edward Hurlock, ${ }^{1}$ Mei Xin,${ }^{1,3}$ Steven G. Kernie, ${ }^{1,2}$ Luis F. Parada, ${ }^{1}$ and Q. Richard Lu ${ }^{1,3}$ \\ ${ }^{1}$ Center for Developmental Biology and Kent Waldrep Foundation Center for Basic Neuroscience Research on Nerve Growth and Regeneration, \\ ${ }^{2}$ Department of Pediatrics, and ${ }^{3}$ Department of Molecular Biology, University of Texas Southwestern Medical Center, Dallas, Texas 75390
}

\begin{abstract}
Much controversy regarding the anatomical sources of oligodendrocytes in the spinal cord and hindbrain has been resolved. However, the relative contribution of dorsal and ventral progenitors to myelination of the cortex is still a subject of debate. To assess the contribution of dorsal progenitors to cortical myelination, we ablated the basic helix-loop-helix transcription factor Olig2 in the developing dorsal telencephalon. In Olig2-ablated cortices, myelination is arrested at the progenitor stage. Under these conditions, ventrally derived oligodendrocytes migrate dorsally into the Olig2-ablated territory but cannot fully compensate for myelination deficits observed at postnatal stages. Thus, spatially restricted ablation of Olig2 function unmasks a contribution of dorsal progenitors to cortical myelination that is much greater than hitherto appreciated.
\end{abstract}

Key words: cortex; knock-out mice; oligodendrocyte; bHLH transcription factor; Olig2; myelination

\section{Introduction}

Cortical myelination by oligodendrocytes facilitates the formation of a highly complex but organized brain structure in vertebrates (Zalc and Colman, 2000). Failure of oligodendrocyte differentiation may contribute to many neurological diseases such as the demyelinating disease multiple sclerosis (Noseworthy et al., 2000; Franklin, 2002). In the developing brain, oligodendrocyte precursor cells (OPCs) are derived from neural progenitors present in the ventricular and subventricular zones at early developmental stages with their maturation and myelination following at postnatal stages (Sauvageot and Stiles, 2002; Miller and Reynolds, 2004; Goldman, 2005).

Much of the controversy regarding the origins of oligodendrocytes in the spinal cord and hindbrain has been recently resolved with the discovery of a late-arising pool of dorsal progenitors that contribute to a larger population of oligodendrocytes derived from progenitors in the ventral neural tube (Cai et al., 2005; Fogarty et al., 2005; Miller, 2005; Vallstedt et al., 2005). However, the relative contribution of dorsal and ventral progenitor cells to oligodendrocyte myelination in the cortex is highly contended in the brain development field (Spassky et al., 2000; Woodruff et al., 2001; Marshall et al., 2003; Miller, 2005). A current view suggests that the majority of cortical oligodendrocytes are initially derived from the ventral telencephalon, populating the dorsal regions by migration and proliferation (Woodruff et al., 2001). Intriguingly, the fate-mapping analysis of progenitor

Received Nov. 3, 2005; revised Dec. 11, 2005; accepted Dec. 18, 2005.

This work was supported by grants from the Wadsworth Foundation, National Multiple Sclerosis Society and March of Dimes Birth Defect Foundation and by National Institutes of Health Grant R01 NS050389 (Q.R.L.). Q.R.L. is a Harry Weaver Neuroscience Scholar and a Basil O'Conner Scholar. We thank Drs. Albee Messing, Susan McConnell, Takuji Iwasato, and Philip Soriano for hGFAP-Cre, Foxg1-Cre, Emx1-Cre, and Rosa26 reporter mice, respectively. We appreciate Drs. Ben Barres and James Goldman for discussion. We are grateful to Dr. Chuck Stiles for support and reagents.

Correspondence should be addressed to Dr. Q. Richard Lu, Center for Developmental Biology, University of Texas Southwestern Medical Center, Dallas, TX 75390. Email: qrichard.lu@utsouthwestern.edu.

D0I:10.1523/JNEUROSCI.4717-05.2006

Copyright $\odot 2006$ Society for Neuroscience $\quad$ 0270-6474/06/261275-06\$15.00/0 cells in the forebrain of rodent neonates and in vitro cortical progenitor culture data suggest that oligodendrocytes can be derived from the dorsal telencephalon (Levison and Goldman, 1993; Gorski et al., 2002; Ivanova et al., 2003). Nonetheless, the extent and timing that dorsal progenitor cells contribute to cortical oligodendrogenesis during brain development remain unknown.

Olig2, a member of the basic helix-loop-helix Olig transcription factor family, plays a critical regulatory role in oligodendroglial cell fate specification in the developing spinal cord (Rowitch, 2004). Olig gene expression in the CNS persists through adulthood (Lu et al., 2000; Zhou et al., 2000), wherein it may participate in the glial response to injury and in brain repair (Arnett et al., 2004; Fancy et al., 2004; Balabanov and Popko, 2005). Genetargeting studies show that Olig2 is essential for the formation of oligodendrocytes and motor neurons in the spinal cord (Lu et al., 2002; Takebayashi et al., 2002; Zhou and Anderson, 2002). However, neonatal lethality of Olig2 knock-out mice impedes the study of Olig2 function in oligodendrocyte myelination during postnatal brain development. In this study, we generated a conditional Olig2 allele using the Cre/lox system by flanking the Olig2 coding region on mouse chromosome 16 with loxP sites (see Fig. $1 A-D)$. Utilizing the critical requirement of Olig2 in oligodendrocyte specification, we examined the role of dorsal progenitors in cortical myelination by deleting Olig2 in these progenitors. Olig2 ablation mediated by cortical progenitor-restricted Cre recombinases results in severe myelination defects in the cortex, and the myelination deficit cannot be fully compensated for by ventrally derived oligodendrocytes. Thus, spatially restricted ablation of Olig2 function unmasks an important contribution of dorsal progenitors to cortical myelination.

\section{Materials and Methods}

Generation of Olig2 conditional mutant mice. To construct the floxed Olig2 targeting vector, we inserted two loxP sites to flank the Olig2 coding region, followed by a neomycin selection cassette, into a $10 \mathrm{~kb}$ SacI-SacII genomic fragment in the pKO-915 vector (Stratagene, La Jolla, CA). The 
A

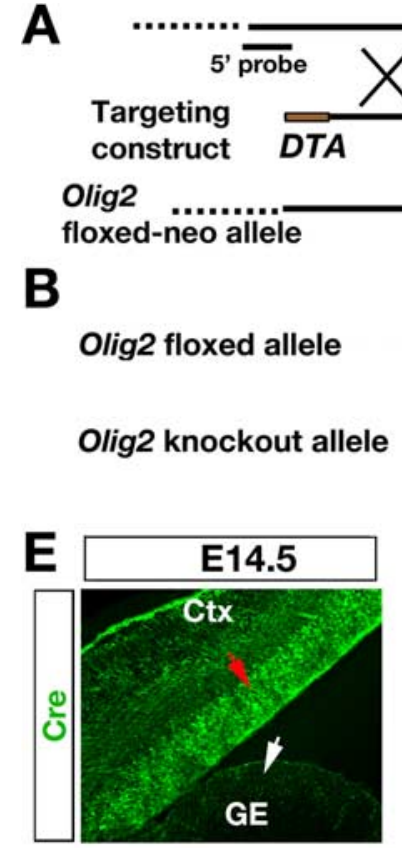

$\mathbf{F}$

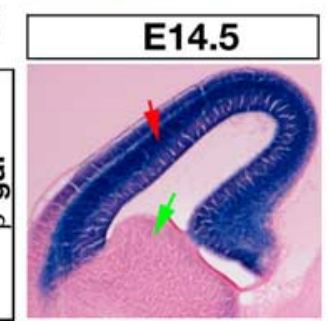

Olig2

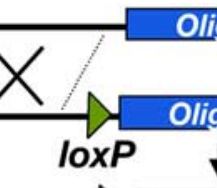

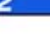

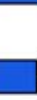
$10 x P$

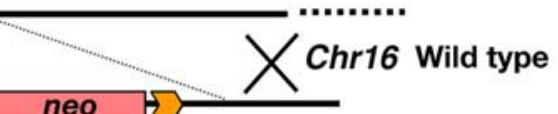
neo

Homologous recombination
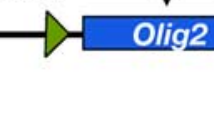
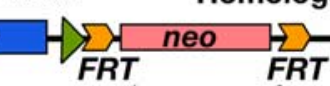

Flpase mediated

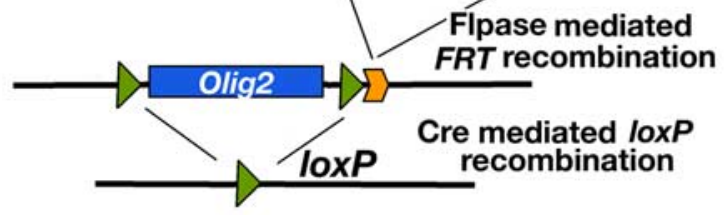

FRT recombination

\section{Cre mediated loxP recombination}

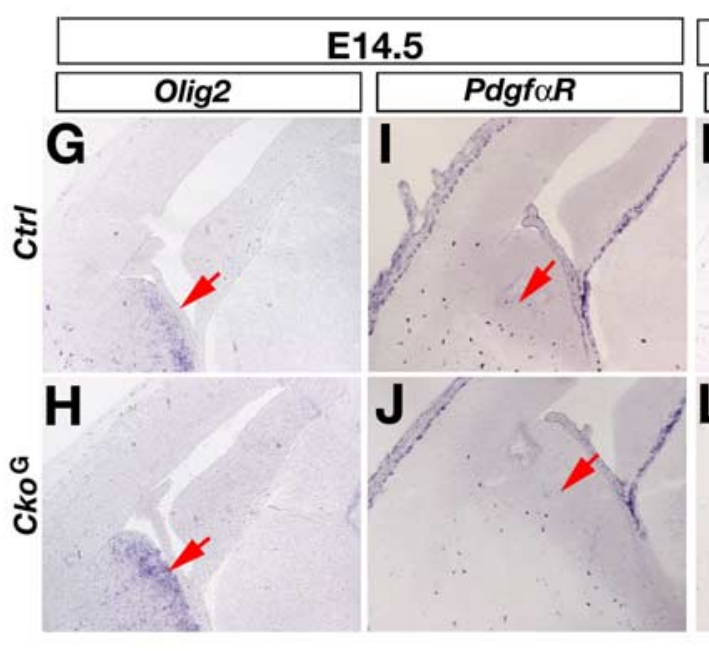

C

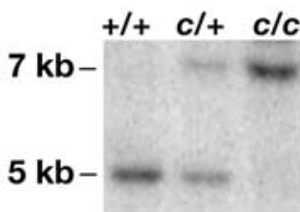

D

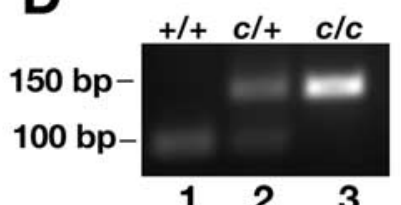

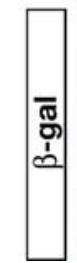

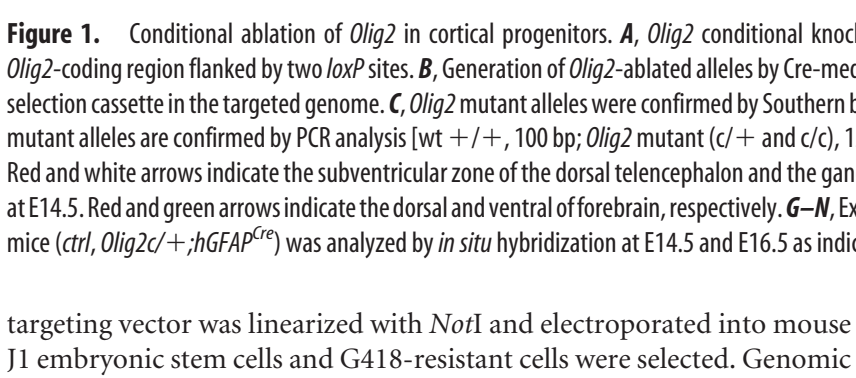
DNA from drug-resistant cells was digested with HindIII and analyzed by Southern blot using a $0.5 \mathrm{~kb}$ or HindIII-SacI fragment as a $5^{\prime}$ probe for Olig2. Transmission of the target allele through the germline was confirmed by Southern blot. Subsequently a PCR strategy was used to identify the mutants. PCR primers $5^{\prime}$ and $3^{\prime}$ are agc cag ccc tca ctt gga gaa ctg ggc ctg and $\mathrm{cgc}$ tag agc ctg ttt tgc acg ttc acc, respectively. The sizes of PCR products for conditional mutants (cko) and wild-types are 350 and 150 bp respectively. Olig2 mutant mice, Cre activator lines, and Rosa26 reporter lines were maintained on a C57BL6/J and 129 SVJ hybrid background. All protocols involving the use of animals were approved by the Institutional Animal Care and Research Advisory Committee at University of Texas Southwestern Medical Center at Dallas.

RNA in situ hybridization. Olig2 control and mutant brains from embryonic and postnatal stages were harvested from anesthetized mice. They were fixed in $4 \%$ paraformaldehyde at $4^{\circ} \mathrm{C}$ overnight, cryoprotected in $20 \%$ sucrose in PBS overnight, embedded in OCT, and cryosectioned at $16 \mu \mathrm{m}$. Digoxigenin-labeled riboprobes were used to perform RNA in situ hybridization as described in Lu et al. (2000). Probes used were as follows: Olig2, $P d g f \alpha R, P l p$, and $M b p$ (Lu et al., 2002).

Immunostaining and histochemistry. Immunostaining and $\beta$-galactosidase staining methods with tissue sections from mouse brains were as described previously (Lu et al., 2002). The following antibodies were used: Cre (1:500; Covance, Berkeley, CA), O4 (1:10; gift from Dr. Alex Gow, Wayne State University, Detroit, MI). Goat anti-mouse sec- ondary antibodies conjugated to Cy2 or Cy3 (Jackson ImmunoResearch, West Grove, PA) were used for double-labeling experiments. Microscopy was performed on a Zeiss (Oberkochen, Germany) LSM 510 confocal microscope.

Electron microscopy. Electron microscopy was performed as described previously. Briefly, the corpus callosum of forebrains from control and Olig2-ablated mice were dissected and fixed overnight by a fixative containing $2 \%$ glutaraldehyde in $0.1 \mathrm{~m}$ cacodylate, $\mathrm{pH} 7.2$. Cross sections of these tissues were processed and thin sections were cut for electron microscopy.

\section{Results}

Olig2 ablation in cortical progenitor cells does not prevent

OPC formation

Olig2 ablation in the dorsal telencephalon is initiated by an $h G F A P^{C r e}$ deleter line (Zhuo et al., 2001) (Fig. 1B). At embryonic stages, the Cre recombinase is predominantly expressed in cortical multipotent progenitor cells (Fig. $1 E$ ), which give rise to neurons, oligodendrocytes, and astrocytes in the developing cortex (Zhuo et al., 2001; Malatesta et al., 2003; Zhu et al., 2005). When this Cre line was crossed with the Rosa26-LacZ reporter line (Soriano, 1999), expression of $\beta$-galactosidase in the progeny of recombined progenitor cells was found in most of neural cell types in the cortex (Fig. $1 F$, red arrow), but is essentially absent in the ganglionic eminence in the ventral forebrain at embryonic day 

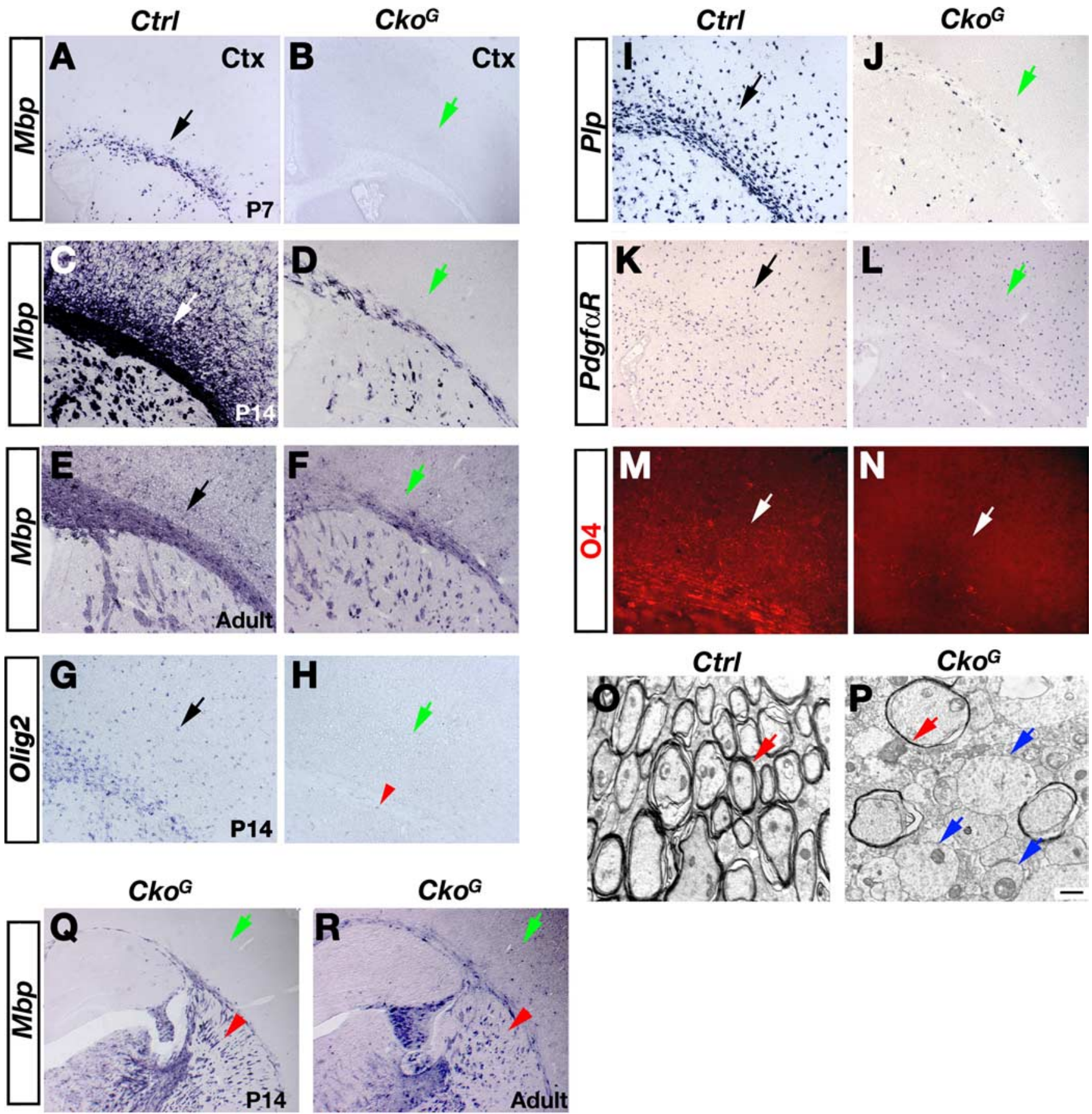

Figure 2. Oligodendrocyte myelination deficit in the Olig2-ablated cortex. $A-N$, Expression of oligodendroglial markers in coronal cortical sections from control and Olig2-ablated $\left(C k O^{G}\right)$ mice at neonatal P7 $(\boldsymbol{A}, \boldsymbol{B})$, perinatal P14 $(\boldsymbol{C}, \boldsymbol{D}, \mathbf{G}-\boldsymbol{N})$, and adult stage P79 $(\boldsymbol{E}, \boldsymbol{F})$ was analyzed by in situ hybridization with antisense probes Olig2, Mbp, Plp/dm20, or PdgfaR, as well as 04 immunostaining as indicated by arrows. Arrowhead in $\boldsymbol{H}$ indicates residual 0 lig $2+$ cells in the cerebral white matter. $\mathbf{O}, \boldsymbol{P}$, Electron micrographs of cross-sections of the corpus callosum from control $(\boldsymbol{O})$ and $C k 0^{G}(\boldsymbol{P})$ animals at P21. Red and blue arrows indicate myelin sheaths and dysmyelinated axons, respectively. $\mathbf{Q}-\boldsymbol{R}$, Expression of $M b p$ mRNA in the ventral forebrain of Olig 2 mutant $\left(C^{6} \sigma^{6}\right)$ mice at P14 $(\boldsymbol{Q})$ and adult P79 (R). Arrows and arrowheads indicate Mbp expression in the cortex and the ventral forebrain, respectively. Scale bar: $\boldsymbol{P}, 500 \mathrm{~nm}$.

14.5 (E14.5) (Fig. 1F, green arrow), suggesting that the Cre activity is mainly confined to dorsal progenitor cells of the developing telencephalon (Fig. 1E). Thus, the initial Olig2 expression in the ganglionic eminence is not removed by Cre recombinase in Olig2c/-; hGFAP ${ }^{C r e}$ embryos at E14.5 (Fig. 1, compare G, H). This is consistent with the formation of $P d g f \alpha R+$ OPCs in the ventral forebrain of these embryos to an extent comparable with the control (Fig. 1J,I). At E16.5, when Olig2 expression appears in the cortex of control embryos (Fig. $1 \mathrm{~K}$ ), hGFAP-Cre activity completely ablates Olig2 expression in this region (Fig. $1 \mathrm{~L}$ ). However, even with Olig2 ablation, OPCs that express $P d g f \alpha R$ are formed in the cortex (Fig. $1 \mathrm{~N}$ ) at levels similar to those seen in controls (Fig. 1M).

We found that there are essentially no Olig2 + cells in the cortex of the Olig2-ablated embryos. Thus, the Olig2-ablated cortex does not appear to be populated by ventral to dorsal migration of unablated Olig2 + OPCs from the ventral forebrain. We considered that Olig2 expression might be ablated by hGFAP-Cre activity en route 
while migrating into the cortex tangentially. However, hGFAP-Cre recombinase expression is confined to the dorsal subventricular zone (Fig. 1E), suggesting the Olig2-negative OPCs present in the Olig2-ablated cortex are mainly derived from dorsal progenitor cells of the telencephalon.

\section{Cortical ablation of Olig2 results in} severe myelination deficits in the cortex Pups with the Olig2Cko; $h$ GFAP ${ }^{\text {Cre }}$ genotype are born at normal Mendelian ratios; however, they develop an abnormal limbclasping reflex and tremors beginning at postnatal week 2 (data not shown), reminiscent of the phenotypes described for dysmyelinating mutants (Sidman et al., 1964; Dupouey et al., 1979; Popko et al., 1987; Nave, 1994; Xin et al., 2005).

Because Olig2 ablation does not affect cortical OPC proliferation, we examined whether OPCs lacking Olig2 could undergo myelinogenesis postnatally. In the Olig2-ablated cortex, a series of premyelinating and myelinating oligodendroglial markers are reduced (Fig. 2A-N). Olig2 expression is essentially absent in the cortex (Fig. $2 H$ ), despite the presence of residual Olig2 + cells in the cerebral white matter (Fig. $2 H$, arrowhead). Expression of premyelinating oligodendrocyte markers such as O4 (Pfeiffer et al., 1993) is undetectable in the cortex at P14 and adulthood except for a small population of these cells present in the white matter (Fig. 2N) (data not shown). At stage P7, no expression of a myelin gene $M b p$ (myelin basic protein) is detectable in mutants (Fig. 2B). From P14 onward, expression of mature oligodendrocyte markers $M b p$ and $P l p$ (proteolipid protein) is not observed in the cortex but is detectable in the white matter of the Olig2-ablated brain at markedly reduced levels (Fig. $2 D, F, J$ ). In contrast, the number of $P d g f \alpha R+$ and NG2 + OPCs in the cortex appears unaltered (Fig. $2 L$ ) (data not shown). These data suggest that the loss of Olig2 causes the oligodendrocyte maturation process to be arrested at a progenitor cell stage before the formation of myelinating oligodendrocytes in the developing cortex.

The absence of myelin-related antigens is accompanied by morphological changes in myelinogenesis as assessed by electron microscopy. Ultrastructural examination of cross sections from the corpus callosum reveals a severe reduction in the number of myelinated axons as well as in the thickness of the myelin sheath formed in Olig2-ablated mice (Fig. $2 P$ ).

We observed considerable myelinating oligodendrocytes formed postnatally in the ventral forebrain of Olig2 mutant mice (Fig. 2Q,R, arrowheads), suggesting that a small population of oligodendrocytes observed in the white matter tract of Olig2 mutants is derived from ventral-to-dorsal migratory oligodendrocytes at postnatal stages.

Populations of dorsally and ventrally derived oligodendrocytes dynamically contribute to cortical myelination

Residual hGFAP-Cre activity detected in the ventral forebrain at postnatal stages (Malatesta et al., 2003) could contribute to cor- tical myelination deficits in the Olig2 mutant mice. To derive independent evidence for the role of cortical progenitors in oligodendrocyte myelination in the cortex, we used a second Cre deleter line, Foxg1-Cre, where Cre activity is restricted to telencephalon progenitors (Hebert and McConnell, 2000; Ferguson et al., 2002). Strikingly, Olig2 ablation mediated by Foxg1-Cre mainly occurs in the dorsal region of the cortex (Fig. $3 G$, red arrow) but not in the ventral forebrain at neonatal stages such as postnatal day 5 (P5) (Fig. $3 H$ ). As with Olig2 ablation by hGFAPCre, expression of myelin genes $M b p$ and $P l p$ in the cortex of Olig2Cko;Foxg1 ${ }^{\text {Cre }}$ mice is undetectable at perinatal stages P12 and $\mathrm{P} 18$ in dorsal cortical regions (Fig. $3 D, E, I, J$, red arrows), in sharp contrast to intense myelin gene expression in control cortices (Fig. $3 A, B$ ).

Despite the defect in cortical oligodendrocyte formation, a ventral-to-dorsal gradient of $M b p$ expression appears in the cortex at perinatal stages (Fig. $3 D, E$ ). By a young adult stage $\mathrm{P} 28$, a large area of the dorsal region of the cortex is populated by myelinating oligodendrocytes expressing $M b p$ (Fig. $3 F$ ), giving the impression that ventrally derived oligodendrocytes progressively migrate toward the dorsal telencephalon beginning at the perinatal stage. A similar ventral-to-dorsal migratory trend exhibited by ventral oligodendrocytes is observed with another oligodendrocyte differentiation marker Plp (Fig. 3I-K). Nonetheless, the absence of myelinating oligodendrocytes in the dorsal region of the cortex persists in young adult Olig2 mutants (Fig. $3 F, K$ ), in contrast to the well distributed oligodendrocytes in cortical regions seen in control mice (Fig. 3C,L).

Strikingly, despite the defect in cortical myelination (Fig. 3O, arrow), in the ventral forebrain, the amount of myelin gene ex- 

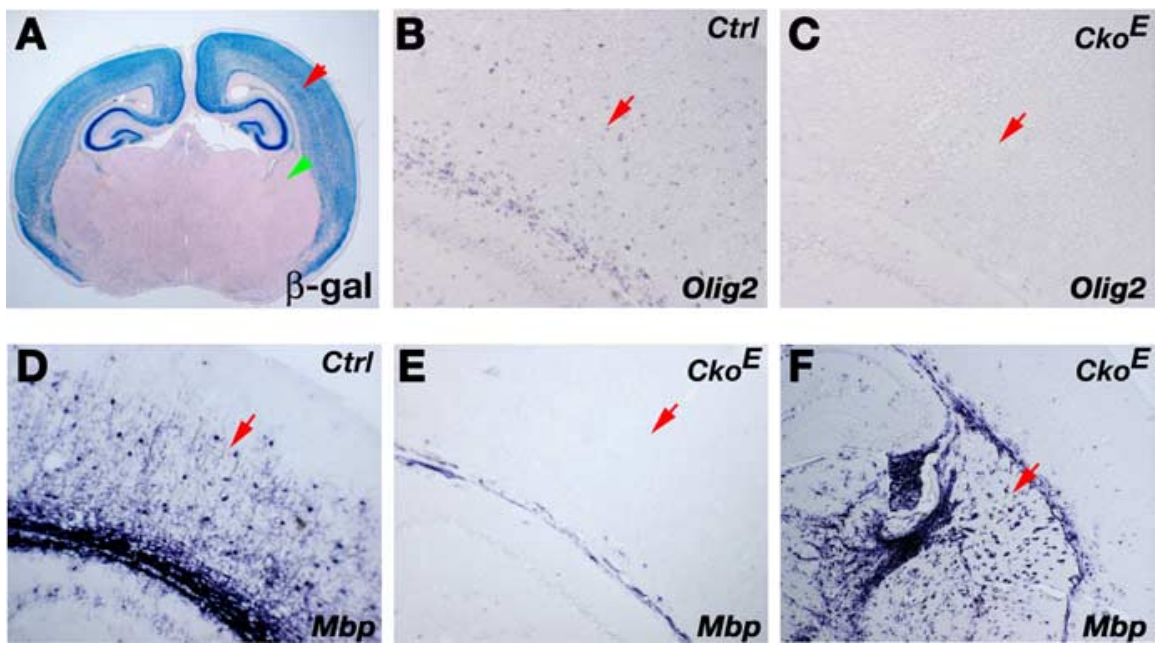

Figure 4. Cortical myelination deficit in 0 lig2 $2 \mathrm{ko}$; $E m \times 1^{\text {Cre }}$ mice. $\boldsymbol{A}, \beta$-Galactosidase activity was examined in coronal brain sections of Emx1-Cre;Rosa26 reporter mice at P14. The red arrow indicates the cortex-restricted $\beta$-galactosidase expression. The green arrowhead indicates the ventral forebrain region such as the striatum. $\boldsymbol{B}-\boldsymbol{F}$, In situ hybridization labeling of 0 lig $2(\boldsymbol{B}, \boldsymbol{C})$ and $\operatorname{Mbp}(\boldsymbol{D}-\boldsymbol{F})$ is shown in the forebrain of control and Olig2 $C \mathrm{ko}, E m \times{ }^{C r e}\left(\mathrm{Cko}^{E}\right)$ mice at P14. Arrows in $\boldsymbol{B}-\boldsymbol{E}$ indicate 0 lig2 and $M b p$ expression in the cortex, respectively. Arrow in $\boldsymbol{D}$ indicates the formation of $M b p+$ oligodendrocytes in the ventral forebrain of Olig2 mutants. Magnifications: $\boldsymbol{A}, 10 \times ; \boldsymbol{B}-\boldsymbol{E}, 100 \times ; \boldsymbol{D}, 40 \times$.

pression (Fig. 3O,P) and the number of $\mathrm{Plp}+$ oligodendrocytes (data not shown) are maintained in Olig2 mutants at levels similar to those of control littermates (Fig. 3, compare $N, P$ ), suggesting that dorsally restricted Olig2 ablation by Foxg1-Cre does not affect ventral oligodendrocyte formation, and partial myelination observed in the Olig2-ablated cortex is likely contributed by ventral migrating oligodendrocytes.

The critical role of dorsal progenitors in cortical myelination can be further confirmed by using an additional cortex-restricted Cre activator, Emx1-Cre, for Olig2 ablation (Fig. 4A-C) (Iwasato et al., 2000; Gorski et al., 2002). Cortical ablation of Olig2 mediated by Emx1-Cre results in severe dysmyelination in the cortex (Fig. 4, compare $D, E$ ), whereas the formation of myelinating oligodendrocytes in the ventral forebrain appears to be normal (Fig. 4F). The cortical dysmyelination phenotypes obtained with independent cortex-restricted Olig2 ablations are in agreement with each other, providing evidence that the dorsal progenitors of the forebrain play a critical role in cortical myelination.

\section{Discussion}

Oligodendrocytes are widely distributed in the brain, however, their specification and differentiation are tightly regulated in a spatially and temporally specified manner (Woodruff et al., 2001; Rowitch, 2004). Previous studies suggest that oligodendroglial populations initially appear in the ventral brain structures (Spassky et al., 2000; Tekki-Kessaris et al., 2001; Woodruff et al., 2001). However, the contribution of dorsal progenitors to cortical myelination remains controversial. This gap in our knowledge may present a challenge for repairing myelin damage in diseases such as multiple sclerosis, in which cortical demyelination is prominent (Peterson et al., 2001; Franklin, 2002).

In the spinal cord and hindbrain, the dorsal progenitors for oligodendrocytes emerge subsequent to a more abundant population of ventral progenitors and they appear to play a relatively minor role in total oligodendrogenesis there (Cai et al., 2005; Fogarty et al., 2005; Vallstedt et al., 2005). By analogy, dorsal progenitors might not play a major role in cortical oligodendrogenesis. In this study, we analyze cortical myelination by ablating an essential oligodendrocyte specification gene Olig2 in dorsal progenitor cells of the developing cortex. Spatially restricted Olig2 ablation leads to a nearly complete absence of myelination in the cortex at early postnatal stages and severe dysmyelination even at adulthood, suggesting that dorsal progenitor cells are a critical source for oligodendrocyte myelination in the developing cortex.

Despite the deficits of cortical myelination, the number of $P d g f \alpha R$-expressing cells appears to be normal in the Olig2ablated cortex, suggesting that differentiation of cortical progenitors up to the OPC stage and proliferation of OPCs do not require Olig2 function. However, absence of O4 expression in the cortical layers continuing through adulthood suggests that Olig2 is required for either the formation of $\mathrm{O} 4+$ premyelinating oligodendrocytes beyond the $P d g f \alpha R+$ OPC stage or O4 expression in OPCs in the developing cortex.

In contrast to the cortex, Olig2 ablation in cortical progenitors does not prevent the formation of myelinating oligodendrocytes in the postnatal ventral forebrain. The presence of a small population of Olig2+ cells and oligodendrocytes expressing O4, Mbp , and Plp in the white matter of Olig2 mutants is likely attributable to the ongoing migration or maturation of premyelinating oligodendrocytes derived from the ventral forebrain, such as the ganglionic eminence (He et al., 2001). These ventrally derived oligodendrocytes contribute to cortical myelination by progressively migrating into the dorsal region of the Olig2-ablated cortex where myelination is limited, however, they cannot fully compensate for the cortical myelination deficits. Contribution of dorsal and ventral progenitors to cortical myelination may occur in a temporally specified manner, however, because the final number and distribution of mature oligodendrocytes are tightly controlled (Barres and Raff, 1994; Calver et al., 1998), the dynamics and extent of the contribution for ventrally derived oligodendrocytes to cortical myelination during normal brain development remain unclear at present. Interestingly, all three mutants with Olig2 ablation develop tremors to a variable extent perinatally, suggesting cortical dysmyelination contributes to this phenotype. The severity of dysmyelination in Cre-mediated Olig2 mutant cortices from different Cre lines may depend on the extent of Olig2 ablation in cortical regions. Nonetheless, Olig2 ablation in the cortical progenitors mediated by independent cortex-restricted Cre activator lines results in consistent myelination deficits in the developing cortex, suggesting that oligodendrocytes of the cortex are largely derived from dorsal progenitors rather than ventral-to-dorsal migrating oligodendrocytes. Unmasking an important dorsal source of myelinating cells for the cortex may illuminate avenues for myelin repair in demyelinating diseases.

\section{References}

Arnett HA, Fancy SP, Alberta JA, Zhao C, Plant SR, Kaing S, Raine CS, Rowitch DH, Franklin RJ, Stiles CD (2004) bHLH transcription factor Olig1 is required to repair demyelinated lesions in the CNS. Science 306:2111-2115.

Balabanov R, Popko B (2005) Myelin repair: developmental myelination redux? Nat Neurosci 8:262-264. 
Barres BA, Raff MC (1994) Control of oligodendrocyte number in the developing rat optic nerve. Neuron 12:935-942.

Cai J, Qi Y, Hu X, Tan M, Liu Z, Zhang J, Li Q, Sander M, Qiu M (2005) Generation of oligodendrocyte precursor cells from mouse dorsal spinal cord independent of Nkx6 regulation and Shh signaling. Neuron 45:41-53.

Calver AR, Hall AC, Yu WP, Walsh FS, Heath JK, Betsholtz C, Richardson WD (1998) Oligodendrocyte population dynamics and the role of PDGF in vivo. Neuron 20:869-882.

Dupouey P, Jacque C, Bourre JM, Cesselin F, Privat A, Baumann N (1979) Immunochemical studies of myelin basic protein in shiverer mouse devoid of major dense line of myelin. Neurosci Lett 12:113-118.

Fancy SP, Zhao C, Franklin RJ (2004) Increased expression of Nkx2.2 and Olig2 identifies reactive oligodendrocyte progenitor cells responding to demyelination in the adult CNS. Mol Cell Neurosci 27:247-254.

Ferguson KL, Vanderluit JL, Hebert JM, McIntosh WC, Tibbo E, MacLaurin JG, Park DS, Wallace VA, Vooijs M, McConnell SK, Slack RS (2002) Telencephalon-specific Rb knockouts reveal enhanced neurogenesis, survival and abnormal cortical development. EMBO J 21:3337-3346.

Fogarty M, Richardson WD, Kessaris N (2005) A subset of oligodendrocytes generated from radial glia in the dorsal spinal cord. Development 132:1951-1959.

Franklin RJ (2002) Why does remyelination fail in multiple sclerosis? Nat Rev Neurosci 3:705-714.

Goldman JE (2005) Lineages of astrocytes and oligodendrocytes. In: Neuroglia (Kettenmann H, Ransom BR, eds), pp 72-84. New York: Oxford UP.

Gorski JA, Talley T, Qiu M, Puelles L, Rubenstein JL, Jones KR (2002) Cortical excitatory neurons and glia, but not GABAergic neurons, are produced in the Emx1-expressing lineage. J Neurosci 22:6309-6314.

He W, Ingraham C, Rising L, Goderie S, Temple S (2001) Multipotent stem cells from the mouse basal forebrain contribute GABAergic neurons and oligodendrocytes to the cerebral cortex during embryogenesis. J Neurosci $21: 8854-8862$

Hebert JM, McConnell SK (2000) Targeting of cre to the Foxg1 (BF-1) locus mediates loxP recombination in the telencephalon and other developing head structures. Dev Biol 222:296-306.

Ivanova A, Nakahira E, Kagawa T, Oba A, Wada T, Takebayashi H, Spassky N, Levine J, Zalc B, Ikenaka K (2003) Evidence for a second wave of oligodendrogenesis in the postnatal cerebral cortex of the mouse. J Neurosci Res 73:581-592.

Iwasato T, Datwani A, Wolf AM, Nishiyama H, Taguchi Y, Tonegawa S, Knopfel T, Erzurumlu RS, Itohara S (2000) Cortex-restricted disruption of NMDAR1 impairs neuronal patterns in the barrel cortex. Nature 406:726-731.

Levison SW, Goldman JE (1993) Both oligodendrocytes and astrocytes develop from progenitors in the subventricular zone of postnatal rat forebrain. Neuron 10:201-212.

Lu QR, Yuk D, Alberta JA, Zhu Z, Pawlitzky I, Chan J, McMahon AP, Stiles CD, Rowitch DH (2000) Sonic hedgehog-regulated oligodendrocyte lineage genes encoding $\mathrm{bHLH}$ proteins in the mammalian central nervous system. Neuron 25:317-329.

Lu QR, Sun T, Zhu Z, Ma N, Garcia M, Stiles CD, Rowitch DH (2002) Common developmental requirement for Olig function indicates a motor neuron/oligodendrocyte connection. Cell 109:75-86.

Malatesta P, Hack MA, Hartfuss E, Kettenmann H, Klinkert W, Kirchhoff F, Gotz M (2003) Neuronal or glial progeny: regional differences in radial glia fate. Neuron 37:751-764.

Marshall CA, Suzuki SO, Goldman JE (2003) Gliogenic and neurogenic progenitors of the subventricular zone: who are they, where did they come from, and where are they going? Glia 43:52-61.
Miller R, Reynolds R (2004) Oligodendroglial lineage. In: Myelin biology and disorders (Lazzarini RA, ed), pp 289-310. New York: Elsevier Academic.

Miller RH (2005) Dorsally derived oligodendrocytes come of age. Neuron 45:1-3.

Nave KA (1994) Neurological mouse mutants and the genes of myelin. J Neurosci Res 38:607-612.

Noseworthy JH, Lucchinetti C, Rodriguez M, Weinshenker BG (2000) Multiple sclerosis. N Engl J Med 343:938-952.

Peterson JW, Bo L, Mork S, Chang A, Trapp BD (2001) Transected neurites, apoptotic neurons, and reduced inflammation in cortical multiple sclerosis lesions. Ann Neurol 50:389-400.

Pfeiffer SE, Warrington AE, Bansal R (1993) The oligodendrocyte and its many cellular processes. Trends Cell Biol 3:191-197.

Popko B, Puckett C, Lai E, Shine HD, Readhead C, Takahashi N, Hunt III SW, Sidman RL, Hood L (1987) Myelin deficient mice: expression of myelin basic protein and generation of mice with varying levels of myelin. Cell 48:713-721.

Rowitch DH (2004) Glial specification in the vertebrate neural tube. Nat Rev Neurosci 5:409-419.

Sauvageot CM, Stiles CD (2002) Molecular mechanisms controlling cortical gliogenesis. Curr Opin Neurobiol 12:244-249.

Sidman RL, Dickie MM, Appel SH (1964) Mutant mice (quaking and jimpy) with deficient myelination in the central nervous system. Science 144:309-311.

Soriano P (1999) Generalized lacZ expression with the ROSA26 Cre reporter strain. Nat Genet 21:70-71.

Spassky N, Olivier C, Perez-Villegas E, Goujet-Zalc C, Martinez S, Thomas J, Zalc B (2000) Single or multiple oligodendroglial lineages: a controversy. Glia 29:143-148.

Takebayashi H, Nabeshima Y, Yoshida S, Chisaka O, Ikenaka K (2002) The basic helix-loop-helix factor olig2 is essential for the development of motoneuron and oligodendrocyte lineages. Curr Biol 12:1157-1163.

Tekki-Kessaris N, Woodruff R, Hall AC, Gaffield W, Kimura S, Stiles CD, Rowitch DH, Richardson WD (2001) Hedgehog-dependent oligodendrocyte lineage specification in the telencephalon. Development 128:2545-2554.

Vallstedt A, Klos JM, Ericson J (2005) Multiple dorsoventral origins of oligodendrocyte generation in the spinal cord and hindbrain. Neuron 45:55-67.

Woodruff RH, Tekki-Kessaris N, Stiles CD, Rowitch DH, Richardson WD (2001) Oligodendrocyte development in the spinal cord and telencephalon: common themes and new perspectives. Int J Dev Neurosci 19:379-385.

Xin M, Yue T, Ma Z, Wu FF, Gow A, Lu QR (2005) Myelinogenesis and axonal recognition by oligodendrocytes in brain are uncoupled in Olig1null mice. J Neurosci 25:1354-1365.

Zalc B, Colman DR (2000) Origins of vertebrate success. Science 288:271-272.

Zhou Q, Anderson DJ (2002) The bHLH transcription factors OLIG2 and OLIG1 couple neuronal and glial subtype specification. Cell 109:61-73.

Zhou Q, Wang S, Anderson DJ (2000) Identification of a novel family of oligodendrocyte lineage-specific basic helix-loop-helix transcription factors. Neuron 25:331-343.

Zhu Y, Harada T, Liu L, Lush ME, Guignard F, Harada C, Burns DK, Bajenaru ML, Gutmann DH, Parada LF (2005) Inactivation of NF1 in CNS causes increased glial progenitor proliferation and optic glioma formation. Development 132:5577-5588.

Zhuo L, Theis M, Alvarez-Maya I, Brenner M, Willecke K, Messing A (2001) hGFAP-cre transgenic mice for manipulation of glial and neuronal function in vivo. Genesis 31:85-94. 